Kelaniya Journal of Human Resource Management

Volume 11, Number 01 - January 2016

DOI: http://doi.org/10.4038/kjhrm.v11i1.28

\title{
Self Determination Theory (SDT): A Review on SDT as a Complementary Theory of Motivation
}

\author{
U. L. T. P. Gunasekare \\ Department of Accountancy, Faculty of Commerce and Management Studies \\ University of Kelaniya, Sri Lanka \\ thamarag@kln.ac.lk
}

\begin{abstract}
Self Determination theory is a comprehensive theory of motivation of human behavior supporting that humans are naturally growth oriented and seek out relationships, connections and challenges that aid humanistic growth and develop their authentic self. This paper discusses the Self Determination Theory (SDT) as a theory of motivation to enlighten the understanding of organizational researchers and practioners to complement the application of traditional motivation theories. SDT provides a useful conceptual tool for motivating people from extrinsic motivation to intrinsic automonus motivation. The extensive literature review on motivation from the SDT perspective was carried out in this study and yielded significant new understanding of work motivation, and suggest opportunities to utilise the theory for research on work-related phenomena. Furthermore, the study provides insight in how the fulfilling the needs for autonomy, competence and relatedness results self regulated human motivation with findings of different research studies. Implications of the study and suggestions for further research are presented.
\end{abstract}

Keywords: Self Determiation Theory, Motivation, Extrinsic Motivation, Intrnsic Motivation, Autonomus Motivation

\section{Introduction}

Self Determination theory (SDT) is a motivation theory based on the premise that people are growth oriented and therefore actively seek motivation to develop their fullest potentials. As such, SDT suggests that humans seek out relationships, connections and challenges that aid humanistic growth and develop the authentic self (Gagne \& Deci, 2005). More precisely psychological needs fulfillment is central to SDT. Individuals have their 
psychological needs for autonomy (psychological freedom), competence (enhancement of one's abilities and skill) and relatedness (meaningful connections with others) and once they are achieved, individuals feel motivation.

This paper discusses the Self Determination Theory (SDT) as a theory of motivation to enlighten the understanding of organizational researchers and practioners. The SDT is another motivtion theory which has received little attention of the researchers to complement the application of traditional motivation theories. Therefore this paper proclaims that SDT provides a useful conceptual tool for motivating people from extrinsic motivation to intrinsic automonus motivation.

The aim of this paper is to expand the understanding of this theory and its relevance to the practical application in a work setting. Furthermore, it is proposed that a consideration of motivation from a self-determination theory perspective will help in reaching a better understanding of the motivation processes, which could inform development of impactful motivational plans for work settings. From the knowldge aspect this paper will creat the attention of the interested researchers and allow them to proceed further studies along this route.

\section{Self Determination Theory}

In the broadest sense, the theory, as it has developed over the past quarter century, discusses that motivation develops from within us, grounded in our basic human needs to develop our skills and capacities, need to act of our own accord, and need to connect to others and to the environment. Deci \& Ryan, (2008) refer these needs as "need for competency, need for autonomy, and need for relatedness." The theory basically assumed that competency, autonomy, and relatedness needs are the basic psychological needs. These psychological needs are further described below.

\subsection{Autonomy}

People want to have a sense of choice, to believe that they are exercising free will. It is important to recognize that, in this context, 
autonomy does not necessarily mean doing things alone. People often choose to do things in concert with others; it is the sense of choice, of feeling volitional, that is paramount. Regarding satisfaction of the need for autonomy, a study by (Deci et al., 1994) revealed three crucial indicators: the possibility to make personal choices, providing a meaningful rationale for the given task or request, and acknowledgment of one's feelings, i.e., taking one's perspective into account.

\subsection{Competence (Mastery)}

It is simply, people like to feel that they are good at what they do. Some have referred to this concept as 'mastery', a reasonable term as long as it does not imply the necessity of reaching the highest possible level of proficiency (Frese, 1989). It is the growing sense of mastery at a task that engages motivation from within, driving the difficult reflective practice required to develop expertise (Hetland, Hetland, Andreassen, Pallesen, \& Notelaers, 2011). Regarding the satisfaction of the need for competence, SDT emphasizes crucial factors such as optimal challenges, encouragement and confidence, timely and constructive feedback, and opportunities to develop capabilities.

\subsection{Relatedness (Purpose)}

People need to feel connected to other people, as noted for millennia by humanists as well as scientists (Frese, 1989). This sense of connectedness may befelt on a direct interpersonal level. It also may be fostered by relating to a group, or to ideals or goals held by a group (including a society or culture); thus, relatedness also has been described as 'sense of purpose'(Allan, Autin, \& Duffy, 2016). As demonstrated by Sheldon, Turban, Brown, Barrick, \& Judge in 2003, some factors in social-context which beneficial to one's satisfaction of the need for relatedness are the experience of acceptance by others, caring, and interest in one's thoughts and feelings by others. Table 1 shows how these three psychological needs can be promoted in a pracitcal work setting. 
Table 01: Approaches to foster the three basic psychological needs as articulated by self-determination theory

\begin{tabular}{|l|l|l|}
\hline \multicolumn{1}{|c|}{ Need for Autonomy } & \multicolumn{1}{|c|}{ Need for Competence } & Need for Relatedness \\
\hline $\begin{array}{l}\text { Take others' } \\
\text { perspectives }\end{array}$ & $\begin{array}{l}\text { Set an optimal level of } \\
\text { challenge. }\end{array}$ & $\begin{array}{l}\text { Acknowledge feelings } \\
\text { and convey Empathy }\end{array}$ \\
\hline Provide choices & $\begin{array}{l}\text { Support the skills } \\
\text { development necessary to } \\
\text { meet the posed challenge. }\end{array}$ & $\begin{array}{l}\text { Create structures to } \\
\text { foster individual } \\
\text { connections }\end{array}$ \\
\hline $\begin{array}{l}\text { Provide a meaningful } \\
\text { rationale when choices } \\
\text { cannot be offered }\end{array}$ & $\begin{array}{l}\text { Give meaningful feedback } \\
\text { framed positively toward the } \\
\text { achievement of competence }\end{array}$ & $\begin{array}{l}\text { Create structures to } \\
\text { foster group and } \\
\text { community } \\
\text { connections }\end{array}$ \\
\hline $\begin{array}{l}\text { Minimize controlling } \\
\text { words }\end{array}$ & \multicolumn{2}{|l}{} \\
\hline
\end{tabular}

(Lyness, Lurie, Ward, Mooney, \& Lambert, 2013).

\section{Research Studies on Self Determination Theory}

As predicted by the SDT, a vast amount of research has demonstrated that the degree of satisfaction of the needs for autonomy, competence, and relatedness predicts optimal functioning and behaviors across various work domains. For example, a great number of studies have shown that the greater a student's need satisfaction is, the greater his or her intrinsic motivation, performance, persistence, and well-being (e.g., Black \& Deci, 2000; Ratelle, Larose, Guay, \& Senécal, 2005; Vallerand, Fortier, \& Guay, 1997). Other domains where the importance of need satisfaction was often demonstrated are health care, sports, relationships, politics, environment, and counseling (Richard M Ryan $\&$ Deci, 2000). Moreover, in support of SDT's claim on the universality of the three needs, needs satisfaction was shown to be of equal importance in collectivist as well as in individualistic cultures. For example, Chirkov, Ryan, Kim, and Kaplan (2003) demonstrated that satisfaction of the need for autonomy was of the same importance for well-being in South Korea, Russia, Turkey, and the United States. Further, it was shown that satisfaction of all 
three needs is crucial for events to be experienced as satisfying in both United States and South Korea (Sheldon, Elliot, Kim, \& Kasser, 2001).

In recent years, the role of need satisfaction has been increasingly investigated within the different working contexts. Studies dealing with this issue have revealed that employee need satisfaction is related to various outcomes such as job satisfaction, well-being, organizational commitment, performance, persistence, work engagement, and acceptance of organizational change (Baard, Deci, \& Ryan, 2004); (Deci et al., 1994); (Guay, Ratelle, \& Chanal, 2008); (Sheldon, Turban, Brown, Barrick, \& Judge, 2003a); (Vondey, 1993). Further, it has been shown that need satisfaction can prevent burnout and deviant behaviors at work (Lian, Ferris, $\&$ Brown, 2012; Broeck et al., 2010). Providing evidence for the universality of needs within the working environment, (Deci et al., 2001) demonstrated that need satisfaction was equally important for work motivation in U.S. and Bulgarian work organizations. Due to the great empirical support of the SDT's framework of need satisfaction across a wide range of settings and in explaining work attitudes and behavior, it can be argued that SDT's basic psychological needs theory provides a powerful approach in motivatiting people.

\section{Self Determination Continuum}

Central to SDT there is a distinction between autonomous motivation and controlled motivation. The theory clearly relates intrinsic rewards and extrinsic rewards with this distinction of auotonomus motivation and controlled motivation. Intrinsic motivation is an example of autonomous motivation. When people engage an activity because they find it interesting, they are doing the activity entirely volitionally (e.g., I work because it is fun). In contrast, being controlled involves acting with a sense of pressure, a sense of having to engage in the actions.

The use of extrinsic rewards in the early experiments was found to induce controlled motivation (Deci \& Station, 1967). SDT postulates that autonomous and controlled motivations differ in terms of both their underlying regulatory processes and their accompanying experiences, and it further suggests that behaviors can be characterized in terms of the degree to which they are autonomous versus controlled. Also, research revealed that 
not only tangible rewards but also threats, deadlines, directives, pressured evaluations, and imposed goals diminish intrinsic motivation. In contrast, choice, acknowledgment of feelings, and opportunities for self-direction, positive feed back were found to enhance intrinsic motivation because they allow people a greater feeling of autonomy (Deci \& Ryan, 1985). At the same trime SDT has been able to identify several distinct types of motivation each of which has specifiable behavioral consequenses for performance. These motivationl behaviors relates with initrinsic and extrinsic motivation.

As indicated above intrinsically motivated behavior, which is propelled by people's interest in the activity itself, is prototypically autonomous. However, an important aspect of SDT is the proposition that extrinsic motivation and intrinsic motivation resides in the same continum and can vary in the degree to which it is autonomous versus controlled (Deci et al., 2001). Activities that are not interesting (i.e., that are not intrinsically motivating) require extrinsic motivation, so their initial enactment depends upon the perception of a contingency between the behavior and a desired consequence such as implicit approval or tangible rewards (Deci et al., 2001). Within SDT, when a behavior is extrinsically motivated it is said to be externally regulated - that is, initiated and maintained by contingencies external to the person. This is the classic type of extrinsic motivation and is a prototype of controlled motivation (Deci \& Ryan, 2008b). When externally regulated, people act with the intention of obtaining a desired consequence or avoiding an undesired one, so they are energized into action only when the action is instrumental to those ends (e.g., I work when the boss is watching). 
Figure 01: Self Determination Continuum (Gagne \& Deci, 2005)

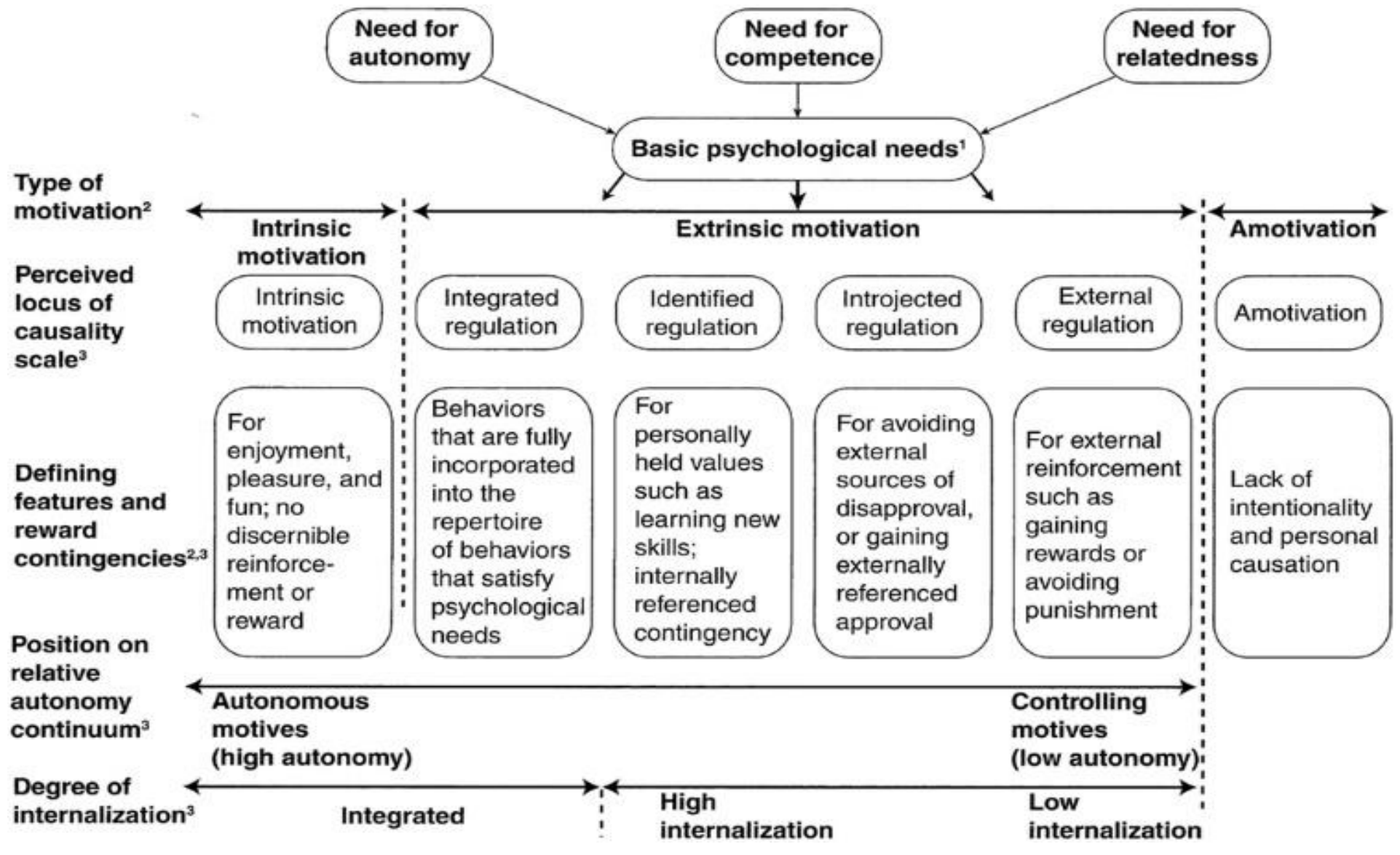


Deci and Ryan (1985) proposed that in this continuum different types of extrinsically regulated behavior can be located. Four types of extrinsic motivation are proposed: external, introjected, identified, and integrated regulations. These reflect behaviors associated with external pressures (external), internal pressures to avoid guilt (introjected), and self-determined motivation associated with personal values and goals (identified). Integrated regulation is more abstract and reflected behaviors which are fully assimilated to the self, which means they have been evaluated and brought into congruence with one's other values and needs (Ryan \& Deci, 2000). Selfdetermination and autonomy increases as one moves from external to integrated regulation. Intrinsic motivation, reflecting enjoyment, interest and inherent satisfaction, is the clearest form of autonomy and it reflects true self determination (Ryan \& Deci, 2000).

Introjected regulation is particularly interesting because the regulation is within the person but is a relatively controlled form of internalized extrinsic motivation (e.g., I work because it makes me feel like a worthy person). With identified regulation, people feel greater freedom and volition because their behavior is more congruent with their personal goals and identities. They perceive the cause of their behavior to have an internal aspect of themselves. For an example if nurses strongly value their patients' comfort and health and understand the importance of doing their share of the unpleasant tasks for the patients' well-being, the nurses would feel relatively autonomous while performing such tasks (e.g.,bathing patients), even though the activities are not intrinsically interesting (Koestner, Otis, Powers, Pelletier, \& Gagnon, 2008).

With integrated regulation, people have a full sense that the behavior is an integral part of who they are, that it emanates from their sense of self and is thus selfdetermined. If integrated, the nurses would not only identify with the importance of the activities for maintaining their patients' comfort and health, but regulation of the activities would be integrated with other aspects of their jobs and lives. (Ryan, 2009) Thus, the profession of nurse would be more central to their identity, they would be more likely to act in ways that are consistent with caring for people more generally, and they could come to appreciate the importance of doing uninteresting activities. Integrated regulation is theorized to represent the most developmentally advanced form of extrinsic motivation, and it shares some qualities with the other type of autonomous motivation, namely, intrinsic motivation (Deci \& Ryan, 2008a). Integrated regulation does not, however, become intrinsic motivation but is still considered extrinsic motivation (even if an autonomous nature is there) because the motivation is characterized not by the person being interested in the activity but rather by the activity being instrumentally important for personal goals (Baard et al., 2004). In short, intrinsic motivation and integrated extrinsic motivation are the two different 
types of autonomous motivation (with identified extrinsic motivation being relatively autonomous).

Importantly, Deci and Ryan (1985) suggest that when the needs for autonomy, competence and relatedness are satisfied, behaviors that may not have been initially intrinsically motivated are 'taken in' and internalized to become more autonomously regulated. Internalization is defined as people taking in values, attitudes, or regulatory structures, such that the external regulation of a behavior is transformed into an internal regulation and thus no longer requires the presence of an external stimulation. (...I work even when the boss is not watching) (Sheldon et al., 2003b). SDT posits a controlled-to-autonomous continuum to describe the degree to which an external regulation has been internalized. The more fully the external stimulation has been internalized, the more autonomous will be the subsequent, motivated behavior.

To summarize, SDT posits a self-determination continuum (see Figure 01) (Deci \& Ryan, 2008a). It ranges from motivation, which is wholly lacking in selfdetermination, to intrinsic motivation, which is invariantly self-determined. Between motivation and intrinsic motivation, along this descriptive continuum, are the four types of extrinsic motivation, with external being the most controlled (and thus the least self-determined) type of extrinsic motivation, and introjected, identified, and integrated being progressively more self-determined.

\section{Conclusion}

This paper strived to describe the process through which self-determination influences positive outcomes of interest in organizations, and discuss how self-determination theory (SDT) can advance contemporary work motivation research. It showed how SDT can be fruitfully applied to understanding constructs related in motivation used in organizational research, such as goal commitment and motivation to learn Although some concepts within SDT are similar to the concepts found in contemporary work motivation theories, we suggest that SDT provides a way of integrating these various strands of thought under a comprehensive meta theory. Indeed, precisely because of such inclusive properties, SDT is playing a prominent role in motivation research.

\section{Bibliography}

Allan, B. A., Autin, K. L., \& Duffy, R. D. (2016). Self-Determination and Meaningful Work: Exploring Socioeconomic Constraints. Frontiers in Psychology, 7(February), 1-9. https://doi.org/10.3389/fpsyg.2016.00071

Baard, P. P., Deci, E. L., \& Ryan, R. M. (2004). Intrinsic Need Satisfaction: A Motivational Basis of Performance and Well-Being in Two Work Settings 1. Journal of Applied Social Psychology, 34(10), 2045-2068. https://doi.org/10.1111/j.15591816.2004.tb02690.x 
Deci, E. L., Eghrarl, H., Patrick, B. C., Leone, D. R., Luke, M., Morris, R., ... Rochester, U. (1994). Facilitaitng Internalizatlon: The Self-Determination Theory Perspective. Journal of Personality, 621(March 1994). https://doi.org/10.1111/j.14676494.1994.tb00797.x

Deci, E. L., \& Ryan, R. M. (2008a). Self-determination theory: A macrotheory of human motivation, development, and health. Canadian Psychology/Psychologie Canadienne, 49(3), 182-185. https://doi.org/10.1037/a0012801

Deci, E. L., \& Ryan, R. M. (2008b). Self-determination theory: A macrotheory of human motivation, development, and health. Canadian Psychology/Psychologie Canadienne, 49(3), 182-185. https://doi.org/10.1037/a0012801

Deci, E. L., Ryan, R. M., Gagné, M., Leone, D. R., Usunov, J., \& Kornazheva, B. P. (2001). Need satisfaction, motivation, and well-being in the work organizations of a former Eastern Bloc country: A cross-cultural study of self-determination. Personality and Social Psychology Bulletin, 27(8), 930-942. https://doi.org/10.1177/0146167201278002

Deci, E. L., \& Station, R. C. (1967). Effects Of Externally Mediated Rewards On Intrinsic Motivation. Journal of Personality and Social Psychology, 18(1), 105-115. https://doi.org/10.1037/h0030644

Frese, M. (1989). Self-determination in a work organization. Journal of Applied Psychology, 74(4), 580-590. https://doi.org/10.1037/0021-9010.74.4.580

Gagne, M., \& Deci, E. L. (2005). Self-Determination Theory and Work Motivation. Journal of Organizational Behavior, 26(4), 331-362. https://doi.org/10.1002/job.322

Guay, F., Ratelle, C. F., \& Chanal, J. (2008). Optimal learning in optimal contexts: The role of self-determination in education. Canadian Psychology/Psychologie Canadienne, 49(3), 233-240. https://doi.org/10.1037/a0012758

Hetland, H., Hetland, J., Andreassen, C. S., Pallesen, S., \& Notelaers, G. (2011). Leadership and fulfillment of the three basic psychological needs at work. Career Development International, 16(5), 507-523. https://doi.org/10.1108/13620431111168903

Koestner, R., Otis, N., Powers, T. A., Pelletier, L., \& Gagnon, H. (2008). Autonomous motivation, controlled motivation, and goal progress. Journal of Personality, 76(5), 1201-1230. https://doi.org/10.1111/j.1467-6494.2008.00519.x

Lyness, J. M., Lurie, S. J., Ward, D. S., Mooney, C. J., \& Lambert, D. R. (2013). Engaging students and faculty: implications of self-determination theory for teachers and leaders in academic medicine. BMC Medical Education, 13.

Ryan, R. M. (2009). Self-determination Theory and Wellbeing. Wellbeing in Developing Countries, 1(June), 1-2.

Ryan, R. M., \& Deci, E. L. (2000). Intrinsic and Extrinsic Motivations : Classic Definitions and New Directions. In Contemporary Educational Psychology (Vol. 67, pp. 54-67). https://doi.org/10.1006/ceps.1999.1020 
Kelaniya Journal of Human Resource Management

Volume 11, Number 01 - January 2016

Sheldon, K. M., Elliot, A. J., Kim, Y., \& Kasser, T. (2001). What Is Satisfying About Satisfying Events? Testing 10 Candidate Psychological Needs. Journal of Personality and Social Psychology, 80(2), 325-339.

Sheldon, K. M., Turban, D. B., Brown, G., Barrick, M. R., \& Judge, T. A. (2003a). APPLYING SELF-DETERMINATION THEORY TO ORGANIZATIONAL, 22(3), 357-393. https://doi.org/10.1016/S0742-7301(03)22008-9

Sheldon, K. M., Turban, D. B., Brown, K. G., Barrick, M. R., \& Judge, T. A. (2003b). Applying Self-Determination Theory To Organizational Research. Research in Personnel and Human Resources Management, 22(3), 357-393. https://doi.org/10.1016/S0742-7301(03)22008-9

Vondey, M. (1993). Follower-Focused Leadership : Effect of Follower Self-Concepts and Self- Determination on Organizational Citizenship Behavior, 1, 52-61. 